\title{
Use of survey data and small area statistics to assess the link between individual morbidity and neighbourhood deprivation
}

\author{
Sarah E Curtis
}

\begin{abstract}
Study objective-The aim of the study was to examine the relationship between sociogeographic factors and health, using a particular social indicator of neighbourhood deprivation.

Design-The study analysed the relationship between health problems (reported by randomly selected respondents to a household survey) and an area social indicator for the neighbourhoods where the respondents lived (based on census data). The area social indicator tested was the underprivileged areas indicator developed by the St Mary's Hospital Department of General Practice, London. Generalised linear interactive modelling with a logistic model was used to test the strength of the relationship between social indicators and morbidity, and to calculate the probability of reporting illness or consultations for survey respondents living in different types of area.

Setting-The study population was derived from three London health districts and their corresponding census enumeration districts.
\end{abstract}

Participants-Responses were obtained from 738 households drawn from the local taxation evaluation list $(66 \%$ of those sampled), and 1384 persons over 16 participated in the survey $(94 \%$ of eligible adults in households surveyed). Of these, 1221 provided complete data on health problems. The survey population was considered representative of the general population in the areas studied since its characteristics were similar to those reported for the population as a whole in the 1981 census.

Results-Within different age and sex groups, those living in very deprived areas, with high underprivileged area scores, were more likely to consult their doctor and to report various indicators of poor health than those living in privileged areas, with low underprivileged area scores.

Conclusions-The underprivileged areas index may provide a useful surrogate indicator to estimate morbidity and use of general practitioner services in small areas. It is likely to be most effective in areas where sociodemographic profiles of the local population are highly contrasting.

There has for some time been a growing interest in methods for assessing the sociogeographic factors associated with health and need for health care on a local scale. This is partly due to concern that the criteria used to allocate resources for health care at the level of the District Health Authority do not reflect local population characteristics which affect the need for health care. ${ }^{12}$ Information on geographical differences in the social and physical environment affecting the need for health care is especially important at a time when growing emphasis is being placed on the development of community health services. ${ }^{3}$ These differences are particularly significant in areas such as London, where socioeconomic conditions can vary dramatically within small geographical zones. "Locality planning" of health and social welfare provision, which is being widely adopted as a means of organising care delivery, requires information on the populations of small areas corresponding to neighbourhoods. ${ }^{4}$

As the focus on local population health needs has sharpened, there has been an increasing interest in measures of social deprivation. One reason for this is that there is a lack of data on morbidity in the community to permit comparison of populations in small geographical areas. Thus attempts to target health care more effectively towards morbidity must be based on surrogate measures of morbidity, such as socioeconomic factors associated with the prevalence of illness. Thunhurst has reviewed some of the small area indicators which have been used for this purpose. ${ }^{5}$ A second reason for interest in measures of social deprivation is that theories concerning the causes of inequalities in health and illness generally suggest that socioeconomic conditions have an impact on health. The use of social indicators, then, may bring us closer to dealing with the causes of illness, as well as helping us to respond more effectively to varying need for the care and treatment of illness.

PROBLEMS OF DEVELOPING INDICATORS OF HEALTH CARE NEED FOR SMALL AREAS

The development of suitable small area indicators of social deprivation to reflect differences in need for health care raises several methodological, theoretical and political problems. For example, difficulties may be encountered because of the unreliability of predicting the health needs of populations from social indicators which are surrogates for more complex definitions of health care needs. Health and social welfare programmes often operate by targeting resources towards areas where a high proportion of the population is considered to be deprived. The reason for this area based planning is that those in deprived areas have a higher than average risk of illness and need for care. However, it is not clear what the 
increased risk associated with deprived areas may be. The effectiveness of a geographical basis for welfare service planning requires careful appraisal from this point of view. ${ }^{6-8}$

The various indices of social deprivation relating to health needs of small areas imply differing theoretical or empirical bases for the selection of the variables to be included, and for the application of weightings to them. ${ }^{5}$ However, such measures are rarely based on direct analysis of the relationship between morbidity and social factors. Without establishing an empirical link between deprivation factors and morbidity, it is unclear how a given socioeconomic indicator should be interpreted in terms of health care need. For example, do illness and need for health care in the population of different neighbourhoods vary directly in proportion to varying magnitude of a social deprivation indicator, or is the relationship more complex?

In this research, I have examined the empirical link between health care "need" (as represented by information on experience of illness and demand for care, reported by individual survey respondents), and an indicator of socioeconomic conditions at the level of small geographical areas. The study therefore describes a method for assessing the sociogeographic factors associated with health status and need for health care at the local scale.

\section{Methods}

The analysis presented here explored the relationship between (a) the propensity to report morbidity and the use of health care amongst individuals responding to a household survey and (b) indicators based on census data summarising the socioeconomic profile of the neighbourhood where the respondents were living. In this case, the neighbourhood is defined as the census enumeration district. The average population size of an enumeration district in the area covered by this study was 340 .

\section{THE SURVEY DATA}

The survey data had been collected from community health surveys conducted at a random sample of private household addresses in three London health districts: Tower Hamlets, Redbridge and Victoria Health Authorities (see fig 1). The addresses were selected by random systematic sample from the local authority rate valuation lists for the three areas. The survey was carried out in 1982 (1984 in Victoria) by means of home interviews with all adult members of the households sampled. ${ }^{9} 10$

Responses were obtained from 738 households (66\% of the households sampled) and 1384 respondents over 16 years of age participated in the survey $(94 \%$ of all eligible adults in the households surveyed). The following results relate to 1221 persons for whom the relevant data were complete for health problems, and 1203 with complete data on general practitioner consultations. The survey data employed in this analysis were demographic information and information on self reported morbidity and general practitioner consultations.

The morbidity measures used were the responses to the Nottingham health profile. This

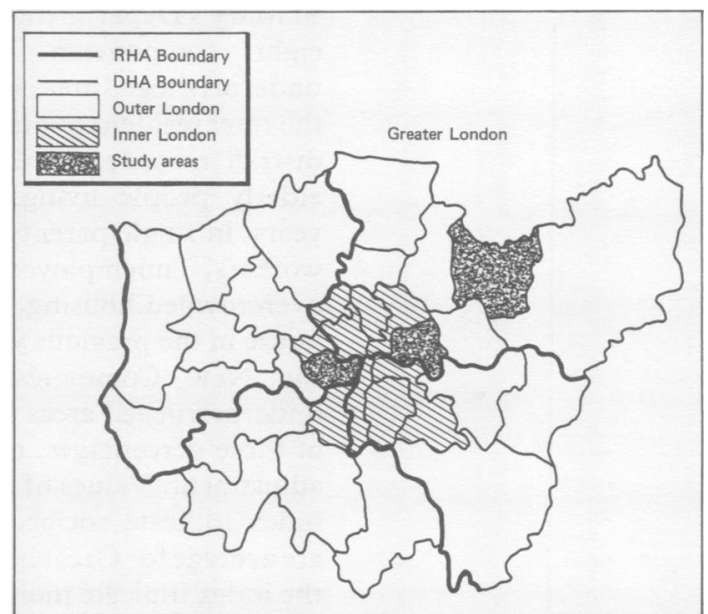

Figure 1 Map of Greater London, showing the three areas from which survey sample was drawn

is a self completion questionnaire developed by a research team at Nottingham University Department of Community Medicine. ${ }^{11} 12$ It comprises 38 items describing aspects of illness. The respondent indicates whether or not each item applies to him- or herself. The responses are used to compile Nottingham health profile scores on six separate dimensions of illness; lack of energy, pain, emotional distress, sleep disturbance, social isolation, physical immobility. The Nottingham health profile responses were taken as indicators of potential need for health care. They are considered in more detail in the discussion below.

In the analysis, the Nottingham health profile results were summarised to binary indicators showing for each dimension whether or not some morbidity was registered by the respondent. This is a simplification of the measures produced from the health profile, which vary from 0 to 100 in relation to the severity of the morbidity registered. However, the non-normal distribution of the complete Nottingham health profile scores presents difficulties for statistical analysis so the technique preferred here was a logistic analysis of binary health profile indicators.

The propensity for general practitioner consultation was also investigated in this analysis, as an alternative measure of "need" or "pressure" on the health services. The instrument used was the question used in the General Household Survey on recent consultation with a doctor. ${ }^{13}$ Respondents were asked:"During the two weeks ending yesterday, apart from any visits to a hospital, did you talk to a doctor for any reason at all, either in person or by telephone?" Supplementary questions established whether the consultation was made under the NHS or paid for privately. The two measures used here were binary indicators of whether or not any consultation took place in the two week period, and whether the respondent consulted the doctor under the NHS.

THE CENSUS DATA FOR AREAS

A socioeconomic indicator for the neighbourhoods where the respondents lived was also employed. This was the Underprivileged Areas Index (UPA), generated by the research team at 
St Mary's Department of General Practice. ${ }^{14}$ The eight components used to calculate the underprivileged areas index are the proportions of the total resident population of each enumeration district recorded in the 1981 census who were elderly people living alone, children under 5 years, in single parent families, unskilled manual workers, unemployed adults, occupants of overcrowded housing, residents who had moved house in the previous year, or immigrants born in the New Commonwealth or Pakistan. The underprivileged areas index is the weighted sum of these percentages, tranformed using an arcsin adjustment. Values of zero for this version of the index indicate socioeconomic conditions which are average for Greater London. Positive values of the index indicate more deprived conditions than average for London, and negative values show more privileged local conditions than average.

The census and underprivileged area index were available for all of the 1520 enumeration districts in the study areas. The element for linking the data was the identifier for the enumeration district used by the office of Population Censuses and Surveys, which was traced for all the survey addresses using local authority registers. Survey responses were obtained from households living in $48 \%$ of the total enumeration districts, distributed randomly throughout the study areas.

STATISTICAL ANALYSIS

The aim was to investigate the relationship between the type of neighbourhood where respondents were living (measured by the underprivileged area score) and the pattern of morbidity and service use which they reported. The underprivileged area index was used as a predictor to estimate the probability of reporting morbidity and the propensity to consult the general practitioner in the populations studied.

The statistical method used here to test the strength of the relationship between social indicators and morbidity was the generalised linear interactive modelling (GLIM) procedure, with a logistic model for analysis of a binary independent variable. Multiple logistic regression by the GLIM procedure was used to test the statistical significance of the association between the underprivileged area score at the enumeration district level and morbidity and service use reported by respondents. The results were used first to test whether the underprivileged area index provided significant additional explanation of variation in the dependent variables when demographic differences were allowed for. The result could also be used to calculate the probability of reporting morbidity or consultations which would be associated with a given underprivileged area index value. The dependent variables were the six Nottingham health profile dimensions, and the measures of recent general practitioner consultations. The underprivileged area index for the respondent's neighbourhood was tested as a predictor variable in each model. For the Nottingham health profile dimensions, sex and age group were also included in the model initially, as predictor variables, because these factors are related to morbidity reporting. For general practitioner consultation, age and sex were initially tested together as independent variables, but since age was not found to provide additional significant explanation, sex and underprivileged area index score were the only predictor variables included.

The significance of an association between the dependent variable and independent variables was indicated in the GLIM results by the change in scaled deviance accompanying the introduction of a new independent variable into the model. The change in scaled deviance is distributed as $\chi^{2}$ for a number of degrees of freedom which corresponds to the change in the degrees of freedom in the model when the new variable is introduced. In the following analysis, associations were considered significant when the chance that the relationship was a random effect was no more than one in $\mathbf{2 0}$ (5\% probability level).

The GLIM results expressed the logistic linear association between the dependent variable (in this case a binary indicator of morbidity or service use) and a set of independent variables (age and sex of respondents and the underprivileged area score for the enumeration district where they lived).

The relationship is expressed in the following form by the logistic model.

$$
\operatorname{logit} P=\log \frac{P}{1-P}
$$

when $P=$ probability that $y=1$, and $y$ is the dependent variable (Nottingham health profile morbidity or general practitioner use).

The logit model was used to estimate the proportion of the population likely to report illness or consult a doctor from a linear combination of the independent variables included in the model. Thus, for example:

$$
p=e^{x} /\left(1+e^{x}\right)
$$

When $p$ is the probability of reporting illness, and $x$ is the sum of the terms and their coefficients in the linear model. This relationship has been applied in other studies to predict the proportion of a population having health problems. ${ }^{15-17}$

\section{Results}

The results in table I show that the sample respondents included similar proportions of people in different age, sex and socioeconomic categories as those recorded in the census for the general populations of the districts from which the sample was drawn. The sample was therefore broadly representative of the general population in the study areas. While the data treated here are not representative of the whole range of conditions existing throughout London, they do correspond to three typical types of area which have been identified in earlier studies. ${ }^{18}$ Tower Hamlets is an example of a deprived area in London's East End, with a large proportion of the population in council housing and in less privileged socioeconomic circumstances. Victoria exhibits the very varied conditions in the West End of inner London, and Redbridge is a typical suburban area with a comparatively privileged social environment. The values of the underprivileged area scores for all the 
Table I Demographic and social characteristics of the survey population compared with the general population of the study areas enumerated in the 1981 Census

\begin{tabular}{|c|c|c|c|c|c|c|}
\hline \multirow[t]{3}{*}{ Characteristics } & \multicolumn{5}{|c|}{ Percentage of populations from: } & \\
\hline & \multicolumn{2}{|c|}{ Tower Hamlets } & \multicolumn{2}{|c|}{ Redbridge } & \multicolumn{2}{|c|}{ Victoria } \\
\hline & $\begin{array}{l}\text { Survey } \\
\text { sample }\end{array}$ & $\begin{array}{l}\text { Census } \\
\text { data }^{\star}\end{array}$ & $\begin{array}{l}\text { Survey } \\
\text { sample }\end{array}$ & $\begin{array}{l}\text { Census } \\
\text { data }^{\star}\end{array}$ & $\begin{array}{l}\text { Survey } \\
\text { sample }\end{array}$ & $\begin{array}{l}\text { Census } \\
\text { data }^{\star}\end{array}$ \\
\hline $\begin{array}{l}\text { Sex } \\
\text { male } \\
\text { female }\end{array}$ & $\begin{array}{l}54 \\
46\end{array}$ & $\begin{array}{l}49 \\
51\end{array}$ & $\begin{array}{l}50 \\
50\end{array}$ & $\begin{array}{l}48 \\
52\end{array}$ & $\begin{array}{l}45 \\
55\end{array}$ & $\begin{array}{l}45 \\
55\end{array}$ \\
\hline $\begin{array}{l}\text { Age (years) } \\
16-44 \\
\text { 44-pensionable } \\
\text { pensionable }\end{array}$ & $\begin{array}{l}53 \\
29 \\
18\end{array}$ & $\begin{array}{l}51 \\
27 \\
22\end{array}$ & $\begin{array}{l}51 \\
30 \\
18\end{array}$ & $\begin{array}{l}51 \\
26 \\
23\end{array}$ & $\begin{array}{l}59 \\
21 \\
19\end{array}$ & $\begin{array}{l}56 \\
22 \\
21\end{array}$ \\
\hline $\begin{array}{l}\text { Housing tenure } \\
\text { owner occupiers } \\
\text { council tenants } \\
\text { other (including private } \\
\text { sector tenants) }\end{array}$ & $\begin{array}{r}1 \\
90 \\
9\end{array}$ & $\begin{array}{r}5 \\
82 \\
13\end{array}$ & $\begin{array}{r}80 \\
12 \\
8\end{array}$ & $\begin{array}{l}73 \\
15 \\
12\end{array}$ & $\begin{array}{l}33 \\
16 \\
50\end{array}$ & $\begin{array}{l}33 \\
16 \\
50\end{array}$ \\
\hline $\begin{array}{l}\text { Car ownership } \\
\text { with car } \\
\text { without car }\end{array}$ & $\begin{array}{l}39 \\
62\end{array}$ & $\begin{array}{l}33 \\
67\end{array}$ & $\begin{array}{l}78 \\
22\end{array}$ & $\begin{array}{l}66 \\
34\end{array}$ & $\begin{array}{l}54 \\
46\end{array}$ & $\begin{array}{l}43 \\
47\end{array}$ \\
\hline $\begin{array}{l}\text { Social class } t \\
\text { non-manual } \\
\text { manual }\end{array}$ & $\begin{array}{l}29 \\
71\end{array}$ & $\begin{array}{l}24 \\
76\end{array}$ & $\begin{array}{l}57 \\
43\end{array}$ & $\begin{array}{l}57 \\
43\end{array}$ & $\begin{array}{l}73 \\
27\end{array}$ & $\begin{array}{l}73 \\
28\end{array}$ \\
\hline $\begin{array}{l}\text { Country of birth } \\
\text { UK } \\
\text { outside UK }\end{array}$ & $\begin{array}{l}76 \\
24\end{array}$ & $\begin{array}{l}81 \\
19\end{array}$ & $\begin{array}{l}89 \\
11\end{array}$ & $\begin{array}{l}88 \\
12\end{array}$ & $\begin{array}{l}64 \\
36\end{array}$ & $\begin{array}{l}61 \\
39\end{array}$ \\
\hline
\end{tabular}

*Data for the general population from the 1981 population census.

tSocial class of head of household, based on Registrar General's classification:

non-manual = classes I, II, IIINM manual = classes IIIM, IV, V

Table II Proportion of respondents reporting illness and recent general practitioner (GP) consultations. Data are percentages except where indicated.

\begin{tabular}{|c|c|c|c|c|}
\hline & \multicolumn{4}{|c|}{ Survey district } \\
\hline & $\begin{array}{l}\text { All } \\
\text { Areas }\end{array}$ & Redbridge & $\begin{array}{l}\text { Tower } \\
\text { Hamlets }\end{array}$ & Victoria \\
\hline $\begin{array}{l}\text { NHP indicator } \\
\text { Lack of energy } \\
\text { Pain } \\
\text { Emotional distress } \\
\text { Sleep problems } \\
\text { Social isolation } \\
\text { Physical immobility }\end{array}$ & $\begin{array}{l}23 \cdot 3 \\
16 \cdot 1 \\
36 \cdot 0 \\
40 \cdot 0 \\
15 \cdot 6 \\
19 \cdot 9\end{array}$ & $\begin{array}{l}22 \cdot 2 \\
13 \cdot 7 \\
34 \cdot 1 \\
41 \cdot 2 \\
13 \cdot 4 \\
19 \cdot 2\end{array}$ & $\begin{array}{l}27 \cdot 8 \\
22 \cdot 4 \\
45 \cdot 0 \\
45 \cdot 0 \\
21 \cdot 5 \\
24 \cdot 4\end{array}$ & $\begin{array}{l}20 \cdot 5 \\
13 \cdot 5 \\
30 \cdot 4 \\
34 \cdot 3 \\
12 \cdot 8 \\
16 \cdot 9\end{array}$ \\
\hline Total number of respondents & (1221) & (454) & (353) & (414) \\
\hline $\begin{array}{l}\text { Recent GP consultation } \\
\text { under the NHS }\end{array}$ & $9 \cdot 4$ & $7 \cdot 1$ & $13 \cdot 3$ & $8 \cdot 3$ \\
\hline $\begin{array}{l}\text { Any recent GP consultation } \\
\text { (including privately) }\end{array}$ & $12 \cdot 2$ & $8 \cdot 0$ & $15 \cdot 2$ & $14 \cdot 4$ \\
\hline Total number of respondents & (1203) & (449) & $(340)$ & $(410)$ \\
\hline
\end{tabular}

$\star \mathrm{NHP}=$ Nottingham health profile; see text for explanation. If the respondent scored more than zero on one of the six dimensions, some health problem was reported for that dimension.

Table III Coefficients from the GLIM analysis of illness, demographic factors and underprivileged area index (UPA) score

\begin{tabular}{|c|c|c|c|c|c|c|}
\hline \multirow{2}{*}{$\begin{array}{l}\text { Dependent } \\
\text { variable }\end{array}$} & \multirow[b]{2}{*}{ Coefficients } & \multicolumn{5}{|c|}{ Terms in the model } \\
\hline & & Constant & $\begin{array}{l}\text { Sex } \\
\text { (female) }\end{array}$ & $\begin{array}{l}\text { Age } \\
45-64\end{array}$ & $\begin{array}{l}\text { Age } \\
65+\end{array}$ & UPA \\
\hline Energy & $\begin{array}{l}\text { Estimate } \\
\text { SEM }\end{array}$ & $\begin{array}{l}-2 \cdot 191 \\
0 \cdot 1461\end{array}$ & $\begin{array}{l}0 \cdot 7351 \\
0 \cdot 1438\end{array}$ & $\begin{array}{l}0.7826 \\
0 \cdot 1644\end{array}$ & $\begin{array}{l}1.441 \\
0.1827\end{array}$ & $\begin{array}{l}0.0182^{\star \star} \\
0.0047\end{array}$ \\
\hline Pain & $\begin{array}{l}\text { Estimate } \\
\text { SEM }\end{array}$ & $\begin{array}{l}-2 \cdot 927 \\
0.1875\end{array}$ & $\begin{array}{l}0.5412 \\
0 \cdot 1702\end{array}$ & $\begin{array}{l}1 \cdot 257 \\
0 \cdot 2004\end{array}$ & $\begin{array}{l}2 \cdot 018 \\
0 \cdot 2126\end{array}$ & $\begin{array}{l}0.0264^{\star \star} \\
0.0054\end{array}$ \\
\hline Emotional distress & $\begin{array}{l}\text { Estimate } \\
\text { SEM }\end{array}$ & $\begin{aligned}-1.066 \\
0.1100\end{aligned}$ & $\begin{array}{l}0.5276 \\
0 \cdot 1232\end{array}$ & $\begin{array}{l}0.2414 \\
0.1406\end{array}$ & $\begin{array}{l}0 \cdot 6141 \\
0 \cdot 1666\end{array}$ & $\begin{array}{l}0.0187^{\star \star} \\
0.0040\end{array}$ \\
\hline Sleep problems & $\begin{array}{l}\text { Estimate } \\
\text { SEM }\end{array}$ & $\begin{array}{l}-1 \cdot 264 \\
0 \cdot 1137\end{array}$ & $\begin{array}{l}0.5805 \\
0.1255\end{array}$ & $\begin{array}{l}0.7070 \\
0 \cdot 1395\end{array}$ & $\begin{array}{l}1 \cdot 856 \\
0 \cdot 1802\end{array}$ & $\begin{array}{l}0.0088^{\star} \\
0.0041\end{array}$ \\
\hline Social isolation & $\begin{array}{l}\text { Estimate } \\
\text { SEM }\end{array}$ & $\begin{array}{c}-2 \cdot 555 \\
0 \cdot 1698\end{array}$ & $\begin{array}{l}0.4215 \\
0 \cdot 1674\end{array}$ & $\begin{array}{l}0 \cdot 7656 \\
0 \cdot 1942\end{array}$ & $\begin{array}{l}1.523 \\
0.2038\end{array}$ & $\begin{array}{l}0.0191^{\star \star} \\
0.0053\end{array}$ \\
\hline Physical immobility & $\begin{array}{l}\text { Estimate } \\
\text { SEM }\end{array}$ & $\begin{array}{l}-2 \cdot 827 \\
0 \cdot 1752\end{array}$ & $\begin{array}{l}0.5407 \\
0.1607\end{array}$ & $\begin{array}{l}1 \cdot 380 \\
0 \cdot 1904\end{array}$ & $\begin{array}{l}2 \cdot 592 \\
0 \cdot 2052\end{array}$ & $\begin{array}{l}0.0176^{\star \star} \\
0.0053\end{array}$ \\
\hline $\begin{array}{l}\text { Recent GP consultation } \\
\text { on NHS }\end{array}$ & $\begin{array}{l}\text { Estimate } \\
\text { SEM }\end{array}$ & $\begin{array}{l}-2 \cdot 844 \\
0 \cdot 1830\end{array}$ & $\begin{array}{l}0 \cdot 8160 \\
0 \cdot 2155\end{array}$ & $\overline{-}$ & - & $\begin{array}{l}0.0264^{\star \star} \\
0.0064\end{array}$ \\
\hline Any recent GP consultation & $\begin{array}{l}\text { Estimate } \\
\text { SEM }\end{array}$ & $\begin{array}{c}-2.540 \\
0.1616\end{array}$ & $\begin{array}{l}0.8160 \\
0.1924\end{array}$ & - & - & $\begin{array}{l}0.0179 \star \\
0.0058\end{array}$ \\
\hline
\end{tabular}

GP $=$ general practitioner

$\star_{p}<0.05, \star \star p<0.01$ enumeration districts in the health districts surveyed (ie, for the full range of neighbourhood conditions existing in the study areas) had a mean of 1.5 and varied from a minimum of -51 to a maximum of +54 . The mean value of the score for the "sample" enumeration districts was 0.8 , and values ranged from -33 to +45 . Of the enumeration districts covered by the sample, about $25 \%$ had an underprivileged area indicator of less than -10 , and the upper quartile range was +10 and over. Table II shows the pattern of self reported morbidity and general practitioner consultation for the sample according to age and sex of the respondents. Women and older people were more likely to report illness. Women also had a higher propensity to report general practitioner consultations. For this reason it is appropriate to control for demographic factors in the analysis. The question to be addressed here was whether a more accurate estimate of the proportion reporting illness and general practitioner use could be obtained by using the underprivileged area score for the area of residence, as well as demographic information about the respondents.

The results of the multiple logistic regression modelling are summarised in table III. The change in scaled deviance resulting from the inclusion of the underprivileged area score into the model was in each case significant at the 5\% level of probability, and in most cases the probability of a chance association was less than $1 \%$. Thus for all the dependent variables tested there was a significant association with underprivileged area score of the area of residence after the relevant demographic characteristics of respondents were taken into account. Table III also shows the coefficients associated with different variables in the model, as well as the standard errors associated with the estimates. Figure 2 shows, for different age and sex groups, the increasing estimated probability of reporting emotional distress on the Nottingham health profile associated with increasing values of the underprivileged area index score of their area of residence. The figure also indicates $95^{\circ}$ o confidence intervals of the estimates. For those in neighbourhoods with very high underprivileged area index values $(+20$ and over) the probability of reporting illness is significantly higher than for those in areas with an average UPA score $(+1)$ or a relatively low score ( -20 or less).

Similarly, fig 3 shows, for men and women, the estimated probability of reported consultation with a general practitioner under the NHS, according to different values of the underprivileged area index for the respondent's area of residence. Again, those living in areas with a high underprivileged area index score were more likely to report a consultation in the last two weeks.

Table IV takes the example of women aged 16-44 to show how the underprivileged area score for the area of residence was related to reported illness on the various Nottingham health profile dimensions. This table shows that for each dimension of illness, the estimated proportion reporting some illness increased as the underprivileged area score increased. 
Figure 2 Estimated probability of reporting emotional distress on the Nottingham health profile (see text) associated with varying values of the underprivileged area index (UPA) score of respondent's area of residence

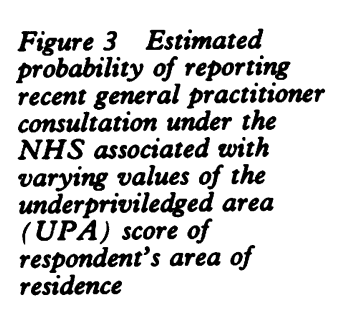

Figure 3 Estimated robability of reporting probent general practitioner UPA) score of residence

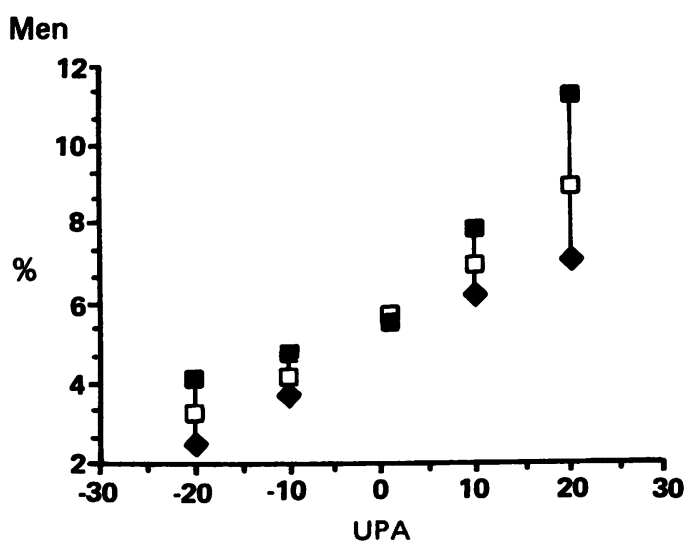

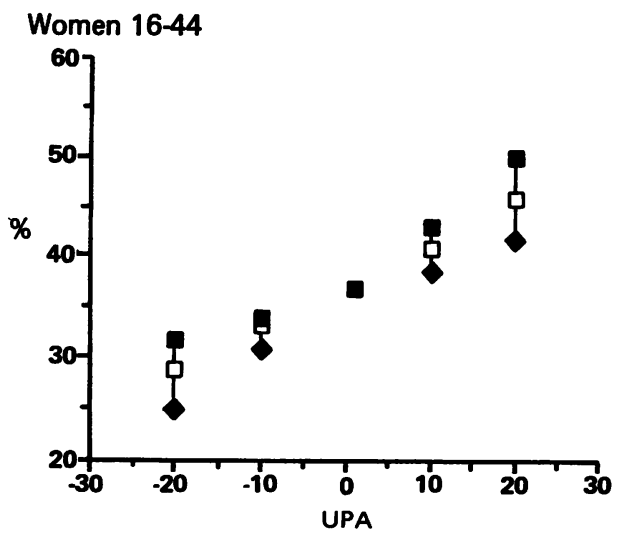
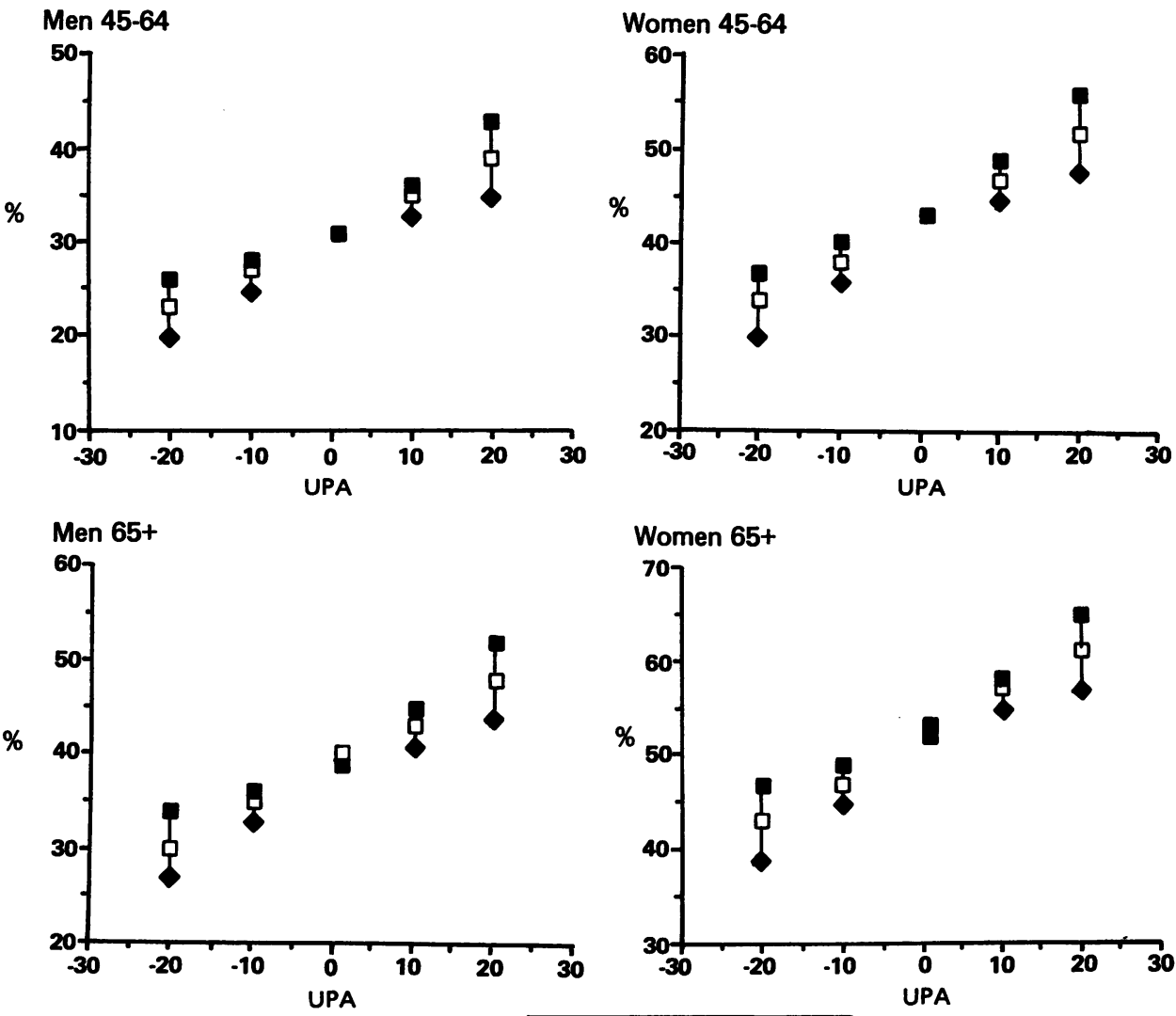

Women 65+

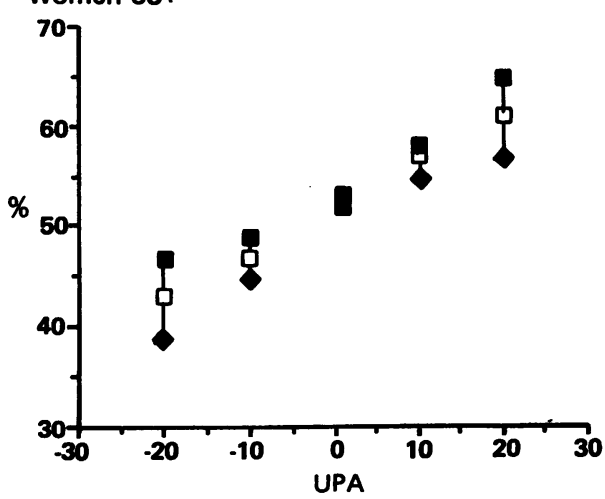

- Upper confidence limit

- Estimated \%

- Lower confidence limit 
Table IV Estimated proportion of women aged 16-44 reporting illness on the Nottingham health profile (NHP, see text) according to the underprivileged area index $(U P A)$ score of their place of residence

\begin{tabular}{lrrr}
\hline & \multicolumn{3}{l}{$\begin{array}{l}\text { UPA score of area } \\
\text { of residence: }\end{array}$} \\
\cline { 2 - 4 } $\begin{array}{l}\text { Estimated \% reporting illness } \\
\text { on NHP dimension: }\end{array}$ & -20 & +1 & +20 \\
\hline Energy & 14 & 19 & 26 \\
Pain & 5 & 9 & 14 \\
Emotional distress & 29 & 37 & 46 \\
Sleep problems & 30 & 34 & 38 \\
Social isolation & 8 & 11 & 15 \\
Physical immobility & 7 & 9 & 13 \\
\hline
\end{tabular}

\section{Discussion}

The analysis reported above showed that for different demographic groups of respondents to the survey, it was possible to make predictions about reported morbidity and use of health care on the basis of area indicators describing the aggregate population in their area of residence. This finding supports the already widely accepted view that living in a socially deprived environment is a significant factor associated with experience of illness and use of health care. It has been suggested that the underprivileged area index or a similar indicator of area deprivation might be used as a measure of relative need for health care for planning purposes, and we may consider the implications of the findings reported here for the value of the underprivileged area index as a measure of population health care need. Conclusions from this analysis should be prefaced by a caveat concerning the extent to which the findings can be generalised. It would not be appropriate to extrapolate these findings to London as a whole, but at the same time the results showed that the sample was typical of the variety of socioeconomic conditions existing in London. It was also found that the enumeration districts occupied by the survey respondents did not represent the extremes of the range of values of the underprivileged area index score existing for enumeration districts in the districts as a whole. Thus the following estimates of probability of health need are for a smaller range of neighbourhood conditions than those existing in reality. Estimation for values of the underprivileged area index score outside the sample range requires extrapolation of the sample results and may be inaccurate.

There are also several questions concerning the interpretation of the measures of morbidity and service use employed here. The Nottingham health profile responses were selected for the analysis because they have been shown to indicate separate dimensions of the impact of illness, which represent aspects of illness common in lay perceptions and are not trivial. At least for some dimensions, individuals who report morbidity in response to the Nottingham health profile are more likely to have consulted a general practitioner recently, so that the Nottingham health profile reflects aspects of illness which are likely to be associated with health care use. ${ }^{12} 15$ Nevertheless these measures of reported distress are very different from clinical diagnoses of health status and it is not clear what health care response might be effective in allieviating this type of illness. Some of the Nottingham health profile dimensions (such as emotional distress) have been found to be associated with general practitioner use. Other dimensions (eg, lack of energy) have been found to differentiate between socioeconomic groups, but were not associated with general practitioner use. ${ }^{15}$ Some of the Nottingham health profile dimensions may therefore imply need for which medical intervention would be considered inappropriate.

The measures of reported consultation with the general practitioner perhaps correspond more directly to the expressed health care need in the population to which health planners normally attempt to respond. Reported use of the general practitioner was not verified against data from medical records, and some error of recall may have affected the accuracy of the response.

Within these limitations of the data analysed, the results do demonstrate a method for evaluating an area indicator such as the underprivileged area index as a measure of health need, and they show that the underprivileged area score of area of residence is a significant predictor of variation in the proportion reporting illness and service use, after demographic factors are taken into account. However, the differences in reported illness and service use are only significant for extreme variations in the underprivileged area index score. There were differences in reported morbidity between those living in enumeration districts with a high value of +20 compared with an average value around +1 . However, residents in enumeration districts with scores ranging between -10 and +10 the differences in reported morbidity might not show significantly different patterns of health need. Large variations in the underprivileged area indicator between highly contrasting areas (eg, from -20 to +20 ) are associated with a smaller order of variation (at most a twofold increase) in the proportion likely to report illness.

The results suggest that while the underprivileged area index may provide a useful surrogate indicator to estimate morbidity and general practitioner use in small areas, it will be most effective for comparing differences between highly contrasting areas. In some parts of London, very deprived populations are located close to very privileged areas within the same health authority district, and in these districts the underprivileged area index might form a useful tool for local planning. In more homogeneous districts the underprivileged area index cannot be expected to predict local variations in reported morbidity and general practitioner use. However, it might provide the basis for comparisons between groups of enumeration districts in different health districts with more variable characteristics. The underprivileged area indicator is available for all enumeration districts in London, so the method described here might be applied more widely if the statistical model were robust for different areas. The predicted population reporting illness in enumeration districts could be estimated on the basis of population in different age and sex categories and underprivileged area score. Thus the method described here might form a bridge between survey data on self reported morbidity and census data on socioeconomic conditions. Since there is a recognised lack of local information about morbidity in the population and it seems unlikely that this can be collected directly, the method has potential for health planning purposes. 
The preliminary work on the data used in this analysis by Dr J Mohan and Mr Meadows, Queen Mary College, is gratefully acknowledged. The author would also like to thank Peter Rice and Dr Brian Jarman, St Mary's Hospital Department of General Practice, for providing part of the data used here, and Mel Slater, Department of Computer Science Queen Mary College, and Dr Denis Bucquet of Institut National de la Santé et Recherche Medicale, France, for advice concerning the statistical aspects of this paper. This research was carried out with support from the Economic and Social Research Council.

Wiles R. Health resources allocation in Greater London; critical guide. London: Greater London Council, 1984.

2 Department of Health and Social Security. Interim report of the Review Committee on the Resource Allocation Working Party formula. London: DHSS, 1986.

3 Department of Health and Social Security Care in the community. London: Her Majesty's Stationery Ofice, 1981.

4 Department of Health and Social Security, Neighbourhood nursing; a focus for care. Report of a working party on community nursing chaired by Mrs J Cumberlege. London: Her Majesty's Stationery Office, 1986.

5 Thunhurst $C$. The analysis of small area statistics and planning for health. Statistician 1984; 34: 93-106.

6 Berthoud R. Where are London's poor? Greater London Research 1976; 36: 5-12.
7 Cullingford S, Openshaw N. Deprived places or deprived people? Newcastle: Centre for Urban and Regional

$8 \mathrm{Kirby} \mathrm{A}$. Geographic contributions to the inner city deprivation debate. A critical assessment. Area 1981; 13: 177-81.

9 Curtis S. Self reported morbidity in London and Manchester. Social Indicators Research 1987; 19: 255-72.

10 Curtis S. Community survey of Victoria district; final report. London: Queen Mary College, 1985.

11 Hunt S, McEwen J, McKenna S. The development of a subjective health indicator. Sociol Health Illness 1980; 2: $231-46$.

12 Hunt S, McEwen J, McKenna S. The Nottingham Health Profile; subjective health status and medical consultations. Soc Sci Med 1981; 15A: 221-9.

13 Office of Population Census and Surveys. General household survey 1981. London: Her Majesty's Stationery Office, survey 1983.

14 Jarman B. Identification of under privileged areas. Br Med $\mathcal{J}$ 1983; 286: 1705-9.

15 Bucquet $D$, Curtis $S$. Socio-demographic variation in perceived illness and the use of primary care. The value of community survey data for primary care service planning. Soc Sci Med 1986; 23: 737-44.

16 Carpenter R. Scoring to provide risk related primary health care; evaluation and up-dating during use. $\mathcal{F} R$ Stat Soc $A$ 1983; 146: 1-32.

17 Cullinan T, Saunders D. Prediction of infant hospital admission risk. Arch Dis Child 1983; 58: 423-7.

18 Jarman B. A survey of primary care in London. Occasional Paper 16. London: Royal College of General Practitioners, 1981 